\title{
Genetic variability of prostaglandin E2 receptor subtype EP4 gene in aspirin-intolerant chronic urticaria
}

\begin{abstract}
Nami Shrestha Palikhe, Hye Jung Sin, Seung Hyun Kim, Hyun Jung Sin, Eui Kyung Hwang, Young Min Ye and Hae-Sim Park

Prostaglandin E2 receptor subtype EP4 (PTGER4) is one of the four subtypes of receptors for prostaglandin E2 (PGE2). Overproduction of cysteinyl leukotriene in mast cells may be related with suppression of PGE2 in patients with aspirin hypersensitivity. Considering the association of PTGER4 in mast cells, urticaria- and aspirin-related disease, we hypothesized the genetic variability of PTGER4 may be associated with aspirin-intolerant chronic urticaria (AICU). The case-control study was performed in 141 with AICU, 153 with aspirin-tolerant chronic urticaria (ATCU) and 174 with normal controls (NCs). PTGER4 promoter single-nucleotide polymorphism was genotyped using a primer extension method with the SNAPshot ddNTP primer extension kit. The functional variability of PTGER4 promoter polymorphism was carried out by dual-luciferase system and electrophoretic mobility shift assay (EMSA) in human mast cells (HMC-1). Furthermore, the effect of aspirin was performed for PTGER4 mRNA expression using real-time PCR, and PGE2 production was checked in HMC-1 cells using ELISA. AICU patients carrying $G G$ genotype at $-1254 \mathrm{G}>\mathrm{A}$ showed significantly higher frequency compared with $N C(P=0.032)$. Similarly, the minor allele frequency, $G$ allele was significantly higher in AICU compared with NC $(P=0.031)$. In vitro functional study demonstrated that the $-1254 \mathrm{G}$ allele had lower luciferase activity $(P<0.001)$ in HMC-1 cells. EMSA finding showed that PTGER4 -1254G produced a specific band. Significantly decreased PTGER4 expression $(P=0.008)$ and PGE2 production by aspirin exposure was confirmed in in vitro HMC cell line model $(P=0.001)$. The PTGER4 $-1254 \mathrm{G}$ allele demonstrated a higher frequency in AICU patients and lower promoter activity with decreased expression of PTGER4 and contributes to the development of AICU. Journal of Human Genetics (2012) 57, 494-499; doi:10.1038/jhg.2012.55; published online 14 June 2012
\end{abstract}

Keywords: aspirin; mast cell; polymorphism; PTGER4; urticaria

\section{INTRODUCTION}

Aspirin ingestion can induce a wide range of clinically recognized allergic reactions, including aspirin-exacerbated respiratory disease (AERD), acetyl salicylic acid (ASA)-intolerant urticaria, chronic rhinitis and anaphylaxis. ${ }^{1}$

Aspirin-intolerant chronic urticaria (AICU), a common type of ASA hypersensitivity presents aggravation of urticaria in patients suffering from chronic urticaria (CU), and its clinical symptoms are more severe compared to aspirin-tolerant $\mathrm{CU}^{2}$ Alteration in eicosanoid metabolism is the suggested pathogenesis for AICU. ${ }^{3}$

The prostaglandin E2 (PGE2), an arachidonic acid metabolite, is synthesized by diverse cell types in response to many stimuli and plays an important role in balancing Th1/Th2 immune responses. ${ }^{4,5}$ PGE2 has various effects such as pro-inflammatory and known to possess anti-inflammatory activities by inhibiting the release of inflammatory mediators from various cells. ${ }^{6}$ PGE2 binds to a specific group of seven-transmembrane domain G-protein-coupled receptors of four subtypes, EP1, EP2, EP3 and EP4.7 Mast cells express EP2, EP3, EP4 receptors and respond to PGE2 and receptor-selective analogs with anticipated biochemical signatures and signaling events. PGE2 strongly suppresses allergic respiratory mucosal inflammation. ${ }^{8}$ PGE2 inhalation before allergen challenge prevents both early- and late-phase response in subjects with asthma ${ }^{6}$ and decreases the levels of prostaglandin D2 (PGD2) that are detected in the bronchoalveolar lavage fluid after allergen challenge. ${ }^{9}$ PGE2 inhibited immunoglobin (Ig)E-mediated histamine and leukotriene $\mathrm{C} 4$ release from human lung mast cells. ${ }^{10}$ PGE2 inhalation prevents bronchoconstriction induced by challenge with nonselective COX inhibitors and abrogates the rise in urinary levels of LTE4, the end product of the cysLTs. ${ }^{11}$ These suggest that PGE2 inhibits mast cell activation in the respiratory tract. Overproduction of cys-LTs is unique to mast cells of AERD patients and is particularly sensitive to suppression by PGE2. ${ }^{12}$ 
Therefore, an alternative hypothesis of ASA hypersensitivity regarding the blocking of synthesis of PGE2 by ASA due to COX inhibition is proposed to AERD and AICU. ${ }^{13}$

Prostaglandin receptor EP4 (PTGER4) is a prostaglandin receptor encoded by the PTGER4 gene in humans and located in chromosome 5p13.1. This protein is one of four receptors identified for PGE2 receptor. Among these subtypes, EP2 and EP4 couple to G stimulatory $\left(\mathrm{G}_{\mathrm{s}}\right)$, resulting in increases of intracellular cAMP concentrations, ${ }^{14}$ while EP3 couples to $G$ inhibitory $\left(G_{\mathrm{i}}\right)$, causing a decrease in cAMP levels. ${ }^{15}$ PTGER1, PTGER2, PTGER3 and PTGER4 polymorphism are the important genetic factors affecting the risk and severity of asthma as well as pathogenesis of AERD. ${ }^{16-18}$ We recently reported that the other prostanoid receptor, thromboxane A2, $(T B X A 2 R)-4684 \mathrm{~T}>\mathrm{C}$ gene polymorphism is associated with aspirin-intolerant acute urticaria (AIAU). TBXA2R -4684 T allele may be associated with lower TBXA2R expression, which may contribute to the development of the AIAU phenotype. ${ }^{3}$

Most candidate gene approaches have focused on leukotrienerelated pathways, whereas there have been no studies evaluating the effects of polymorphisms in PGE2 receptor genes on the development of AICU. Although PTGER4-1254A $>\mathrm{G}$ promoter polymorphism was previously studied in the case of AERD, ${ }^{16}$ no association study was noted in the case of AICU and functional study has not reported till now. Therefore, to replicate the effects of this promoter polymorphism in the other major phenotype of ASA hypersensitivity such as AICU, we performed genetic association study and to confirm the functional significance of promoter single-nucleotide polymorphism (SNP), we performed functional study in human mast cell 1 (HMC-1). The objective of this study was to determine the genetic contribution of SNPs in the PTGER4 promoter region and its functional study to the phenotype of AICU.

\section{MATERIALS AND METHODS}

\section{Study subjects}

Two groups of CU patients, AICU $(n=141)$ patients and aspirin-tolerant chronic urticaria (ATCU, $n=153$ ) based on the results of oral provocation up to $500 \mathrm{mg}$ aspirin (Rhonal; KunWha Pharmaceutical, Seoul, Korea) were enrolled which were described previously. ${ }^{5}$ AICU patients who had AERD were excluded. Normal healthy controls (NC, $n=174$ ) with no personal or family history of allergic diseases or aspirin or drug hypersensitivity were recruited from the general Korean population. Informed consent was obtained from all subjects, and the institutional review board of Ajou University Hospital approved the study. Skin-prick tests were performed with 55 common aeroallergens (Bencard, West Sussex, UK), and atopy was defined as one or more positive reactions to common inhalant allergens. Total IgE concentrations were measured using the UniCAP system (Phadia, Uppsala, Sweden) according to the manufacturer's instructions.

\section{DNA extraction, SNP identification and genotyping}

Total genomic DNA was isolated from the peripheral blood of patients with AICU, ATCU and NC using a commercially available DNA isolation kit (Gentra Genomic DNA purification kit; Qiagen, Valencia, CA, USA) according to the manufacturer's protocol.

PTGER4 gene in promoter region infront of exon 1 was examined for singlenucleotide polymorphisms (SNPs) using the ABI Prism 3100 DNA analyzer (Applied Biosystems, Foster City, CA, USA). We previously identified four polymorphisms of $-1598 \mathrm{~T}>\mathrm{C}(\mathrm{rs} 45437592),-1529 \mathrm{~T}>\mathrm{C}(\mathrm{rs} 413301)$, $-1307 \mathrm{C}>\mathrm{T}(\mathrm{rs} 10039983)$ and $-1254 \mathrm{~A}>\mathrm{G}(\mathrm{rs} 45613037)$ in the promoter region, and found significant association of $-1254 \mathrm{~A}>\mathrm{G}$ with AERD. ${ }^{16}$ Therefore, in this study, we chose $-1254 \mathrm{~A}>\mathrm{G}$ SNP for genotyping with AICU, ATCU and NC using a primer extension method and the SNAPshot ddNTP primer extension kit. (Applied Biosystems, Foster City, CA, USA). The primer used for genotyping of $-1254 \mathrm{~A}>\mathrm{G}$ (rs45613037) SNP is forward primer,
$5^{\prime}$-CTCCAACTCCTTTTATGGTG- $3^{\prime}$ and reverse primer, $5^{\prime}$-GGCTGTTCATC TTCCTCTC- $3^{\prime}$ and genotyping primer, $5^{\prime}$-GCGTGAAAACCACGGGAGCCG CCCC- $3^{\prime}$.

\section{Statistical analysis}

The $\chi^{2}$-tests were used to detect a significant departure in genotype frequency from Hardy-Weinberg equilibrium at promoter SNP. Differences in the mean values of phenotypic characteristics among AICU patients were compared using $\chi^{2}$-test or Fisher's exact test and independent $t$-test. Continuous variables that did not have a normal distribution, such as the levels of serum total IgE, were log-transformed. Differences in the genotype frequency between the two groups were examined with the $\chi^{2}$-test and three logical regression models (co-dominant, dominant, recessive) were used after accounting for age and sex covariates. The dual-luciferase assay was assessed using an independent $t$-test. All statistical analyses were performed using SPSS version 12.0 (SPSS, Chicago, IL, USA). Statistical significance was established as $P \leqslant 0.05$.

\section{Preparation of the PTGER4 construct for promoter assay}

A 214-bp fragment of the human PTGER4 gene was prepared by PCR amplification using either -1254AA homozygous or -1254 GG homozygous human genomic DNA as a template (forward primer, 5'-GAGTTCCCACT CCGCACCTC- $3^{\prime}$ and reverse primer, $5^{\prime}$-TCGCCTTTCCACCCTCTGTAC- ${ }^{\prime}$ ). Each PCR product was gel-purified with an agarose gel purification kit (iNtRON Biotechnology, Deajeon, Korea) and ligated into TA vector (Invitrogen, Deajeon, Korea). The plasmid was digested with XhoI and HindIII (Takara, Shuzo, Japan) and ligated into a similarly digested pGL3-basic luciferase reporter vector (Promega, Madison, WI, USA) using T4 DNA ligase (iNtRON Biotechnology). All constructs were verified by direct sequencing. Plasmid DNAs were prepared from these constructs using an Endo Free Plasmid Maxi kit (Qiagen, Hilden, Germany). Plasmid DNA concentrations and purity were assessed by UV spectrophotometry and agarose gel electrophoresis.

\section{Transient transfection for luciferase activity}

Transfection was performed in HMC-1 cells and repeated in U937 and JurkatT cells. Detailed transfection protocols were described in our previous study. ${ }^{19}$ HMC-1 was transfected using a microporator (model MP-100; Digital Bio Technology, Seoul, Korea) and PMK-1096 (Digital Bio Technology) according to the manufacturer's instructions. Briefly, 24-well plates were filled with $1000 \mu$ of Iscove's modified Dulbecco's medium containing $10 \%$ fetal bovine serum without antibiotics. Plates were incubated in a humidified incubator at $37^{\circ} \mathrm{C}$ under $5 \% \mathrm{CO}_{2}$. HMC-1 cells $\left(2 \times 10^{5}\right)$, reporter plasmid DNA containing PTGER4 $(1 \mu \mathrm{g})$ and Renilla plasmid DNA $(5 \mathrm{ng})$ were suspended in Solution $\mathrm{R}(10 \mu \mathrm{l})$. The incorporation tube was filled with Solution E $(3 \mathrm{ml})$. Cell and DNA mixtures were inserted into the microporator pipette station. HMC-1 cells were shocked using $1750 \mathrm{~V} / 20 \mathrm{~mA} /$ plus width 1 . The samples were transferred to preincubated 24-well plates and incubated for $24 \mathrm{~h}$.

Cells were lysed with passive lysis buffer (Promega), and $100 \mu$ l of lysate were added to each well. A 20 - $\mu$ l aliquot from each well was assayed for luciferase activity using a dual-luciferase reporter assay kit (Promega) and Clarity Luminescence microplate reader (BioTek, Winooski, Vermont, USA). The pGL3-control (Promega) and the promoter-less pGL3-basic vectors were used as positive and negative controls, respectively. Transfection efficiency was determined by measuring Renilla activity using a dual-luciferase reporter assay kit (Promega) after co-transfection of the reporter construct and Renilla control vector.

\section{Nuclear extract preparation and EMSA}

HMC-1 cells were washed with ice-cold phosphate-buffered saline prior to suspension in ice-cold hypo osmotic buffer (10 mM HEPES, $2 \mathrm{mM} \mathrm{MgCl}_{2}$, $0.1 \mathrm{~mm}$ EDTA, $10 \mathrm{~mm} \mathrm{KCl}, 1 \mathrm{~mm}$ dithiothreitol, $1 \mathrm{~mm}$ phenymethylsulfonyl fluoride, $1 \mathrm{~mm} \mathrm{NaVO}, 10 \mathrm{~mm} \mathrm{NaF}$ and $1 \times$ protease inhibitors). Cells were incubated on ice for $10 \mathrm{~min}, 0.2 \%$ Nonidet P-40 was added, and the cells were incubated again for $15 \mathrm{~min}$. After centrifugation at $15000 \times \mathrm{g}$ for $30 \mathrm{~s}$, the pellets were suspended in cold saline buffer containing $50 \mathrm{~mm}$ HEPES, $50 \mathrm{~mm}$ $\mathrm{KCl}, 300 \mathrm{~mm} \mathrm{NaCl}, 0.1 \mathrm{~mm}$ EDTA, $10 \%$ glycerol, $1 \mathrm{~mm}$ dithiothreitol, $1 \mathrm{~mm}$ 
phenymethylsulfonyl fluoride, $1 \mathrm{~mm} \mathrm{NaVO}_{3}, 10 \mathrm{~mm} \mathrm{NaF}$ and $1 \times$ protease inhibitor. The mixture was incubated on ice for $30 \mathrm{~min}$. After centrifugation at $15000 \times g$ for $30 \mathrm{~min}$ at $4{ }^{\circ} \mathrm{C}$, the supernatants containing the nuclear proteins were collected. The protein concentrations were determined by Bradford assay. Nuclear protein aliquots $(5 \mu \mathrm{g})$ were stored at $-80^{\circ} \mathrm{C}$ until use. Doublestranded oligonucleotides for PTGER4 and the specific competitor SP-1 were used as probes for electrophoretic mobility shift assay. The double-stranded oligonucleotides were annealed at $95{ }^{\circ} \mathrm{C}$ for $5 \mathrm{~min}$ and gradually cooled at room temperature. The double-stranded DNA probes were radiolabeled at their $5^{\prime}$-ends using DNA polymerase I (Klenow; Promega) and $\left[\alpha^{-32} \mathrm{P}\right]$-CTP. A $10-\mu \mathrm{l}$ reaction mixture comprising nuclear protein $(5 \mu \mathrm{g}), 75.2 \mathrm{mM} \mathrm{NaCl}$, $20 \mathrm{~mm}$ HEPES, $1 \mathrm{~mm}$ EDTA, $5 \%$ glycerol, $0.0504 \mathrm{~mm} \mathrm{MgCl}_{2}, 5 \mathrm{~mm}$ dithiothreitol, $1 \mathrm{~mm} \mathrm{NaVO}, 10 \mathrm{~mm} \mathrm{NaF}, 400 \mathrm{ng}$ of bovine serum albumin, and $250 \mathrm{ng}$ of poly (dI-dC) was preincubated on ice for $20 \mathrm{~min}$. Radiolabeled probe $(0.2 \mathrm{pmol})$ was added, and the reaction was incubated on ice for another $30 \mathrm{~min}$. The reaction mixture was then subjected to electrophoresis in a native $6 \%$ polyacrylamide gel. A competition experiment was performed using unlabeled, blunt-ended competitor oligonucleotides added to the binding reaction prior to the addition of radiolabeled oligonucleotide. Gels were dried, and radioactivity was detected using a FLA3000 scanner (Fuji Photo Film, Tokyo, Japan).

ASA decreased the PTGER4 mRNA expression in HMC-1 cell line HMC-1 cell line $\left(5 \times 10^{5}\right)$ was stimulated with ASA at $2 \mathrm{~mm}$ of dose for $24 \mathrm{~h}$ and cells were harvested and total RNA was extracted from cells using easy-blue reagent (iNtRON Biotechnology) according to the manufacturer's instruction. cDNA was synthesized, confirmed and real-time PCR was performed to check the mRNA expression of PTGER4 using PTGER4-specific primers $5^{\prime}$-tgaacagcccagtgaccatc- $3^{\prime}$ as a forward primer and $5^{\prime}$-accaacaaagtgcccaacag- $3^{\prime}$ as a reverse primer. Normalization was performed using $\beta$-acting primer $5^{\prime}$-tcct tctgcatcctgtcggc- $3^{\prime}$ as a forward primer and $5^{\prime}$-caagagatggccacggctgc- $3^{\prime}$ as a reverse primer.

\section{ASA decreased the PGE2 production from HMC-1 cell line}

HMC-1 cell line $\left(5 \times 10^{5}\right)$ was stimulated with phorbol-12-myristate 13acetate $10 \mathrm{ng} \mu \mathrm{l}^{-1}$ and $10 \mu \mathrm{M} \mathrm{Ca}{ }^{2+}$ for $30 \mathrm{~min}$ using IMDM serum-free media. Cells were washed with phosphate-buffered saline and aspirin $2 \mathrm{~mm}$ was treated for $24 \mathrm{~h}$. Supernatant was collected and measured PGE2 production using prostaglandin E2 ELISA kit (Cayman, 514010, Ann Arbor, MI, USA).

\section{RESULTS}

Clinical characteristics of the study subjects

The clinical characteristics of the study population are summarized in Table 1 . The atopy rate and total serum IgE (log-transformed) level were significantly higher in AICU groups compared with the ATCU and NC groups $(P<0.001, P<0.001)$, respectively.

\section{Genotype and allele frequencies of the PTGER4 gene}

The genotype distribution of the promoter polymorphism $-1254 \mathrm{~A}>\mathrm{G}$ of PTGER4 did not differ significantly from HardyWeinberg equilibrium (data were not shown, $P>0.05$ ), which was shown by $\chi^{2}$-test. The genotype frequency of PTGER4 $-1254 \mathrm{~A}>G$ differed significantly between the AICU and NC groups in the codominant model (Table 2); however, no significant difference was noted between the AICU and ATCU groups. AICU patients demonstrated a significantly higher frequency of the PTGER4 $-1254 A>G$ homozygous GG genotype compared with NC subjects, and the AA genotypes occurred significantly less frequently in AICU patients than in NC subjects $(P=0.032)$.

\section{Effect of the PTGER4 -1254A $>$ G polymorphism on promoter activity}

To assess whether the PTGER4 $-1254 A>G$ polymorphism is associated with altered promoter activity, constructs containing either PTGER4 $-1254 A$ or PTGER4 $-1254 G$ and a luciferase reporter gene were transfected into HMC-1 cells. Luciferase activity was significantly lower with the PTGER4 - 1254G construct than with the -PTGER4 $-1254 A$ construct $(P<0.001$; Figure $1 \mathrm{~b})$. Further transfection experiments performed in Jurkat-T cell and U937 cells yield similar results: significantly lower promoter activity with the PTGER4 -1254G

Table 1 Clinical characteristics of the study subject

\begin{tabular}{|c|c|c|c|c|c|c|}
\hline & \multirow[b]{2}{*}{$\operatorname{AICU}(\mathrm{N}=141)$} & \multirow[b]{2}{*}{$\operatorname{ATCU}(\mathrm{N}=153)$} & \multirow[b]{2}{*}{$N C(N=174)$} & \multicolumn{3}{|c|}{ P-value } \\
\hline & & & & AICU vs ATCU & AlCU vs NC & ATCU vs NC \\
\hline Sex (male/total) & 69/141 (48.9\%) & 73/153 ((47.7\%) & $77 / 174$ (44.3\%) & 0.907 & 0.428 & 0.579 \\
\hline Age (years) & $35.44 \pm 11.54 / 141$ & $39.39 \pm 11.71 / 153$ & $30.97 \pm 10.68 / 173$ & 0.004 & $<0.001$ & $<0.001$ \\
\hline Atopy (presence/total) & $101 / 140(72.1 \%)$ & 75/152 (49.3\%) & 16/142 (11.3\%) & $<0.001$ & $<0.001$ & $<0.001$ \\
\hline Log(serum total IgE $\left.\left(I U \mathrm{ml}^{-1}\right)\right)$ & $5.20 \pm 1.05 / 121$ & $4.69 \pm 1.11 / 144$ & $3.57 \pm 1.30 / 44$ & $<0.001$ & $<0.001$ & $<0.001$ \\
\hline
\end{tabular}

Abbreviations: AICU, aspirin-intolerant chronic urticaria; ATCU, aspirin-tolerant chronic urticaria; NC, normal control.

$P$-values less than 0.05 were indicated in bold.

Table 2 The genotype and allele frequencies of PTGER4 gene polymorphism

\begin{tabular}{|c|c|c|c|c|c|c|c|}
\hline \multirow[b]{2}{*}{ Loci } & \multirow[b]{2}{*}{ Genotype } & \multirow[b]{2}{*}{$\operatorname{AICU}(\mathrm{N}=141)$} & \multirow[b]{2}{*}{$\operatorname{ATCU}(\mathrm{N}=153)$} & \multirow[b]{2}{*}{$N C(\mathrm{~N}=174)$} & \multicolumn{3}{|c|}{ P-value } \\
\hline & & & & & AlCU vs ATCU & $A I C U$ vs $N C$ & ATCU vs NC \\
\hline \multirow[t]{4}{*}{$-1254 A>G$} & AA & 76 (53.9\%) & 85 (55.6\%) & $107(61.5 \%)$ & ${ }^{\mathrm{a}} 0.86$ & ${ }^{\mathrm{a}} 0.032$ & ${ }^{a} 0.108$ \\
\hline & $A G$ & $54(38.3 \%)$ & 59 (38.6\%) & 59 (33.9\%) & bo.697 & bo.075 & bo.239 \\
\hline & $\mathrm{GG}$ & $11(7.8 \%)$ & $9(5.9 \%)$ & $8(4.6 \%)$ & ${ }^{\circ} 0.982$ & ${ }^{\circ} 0.075$ & ${ }^{\circ} 0.16$ \\
\hline & $q$ & 0.27 & 0.252 & 0.216 & 0.861 & 0.031 & 0.112 \\
\hline
\end{tabular}

Abbreviations: AICU, aspirin-intolerant chronic urticaria; ATCU, aspirin-tolerant chronic urticaria; NC, normal controls.

Each $P$-value was calculated with a ${ }^{a}$ co-dominant ( $A A$ vs $G G$ ), bdominant ( $A A+A G$ vs $G G$ ) and crecessive model (AA vs $\left.A G+G G\right)$, respectively.

The fourth $P$-value was calculated according to minor allele frequency, q. logistic regression analysis was applied to control for age and sex as covariates in all models.

$P$-values less than 0.05 were indicated in bold. 
a
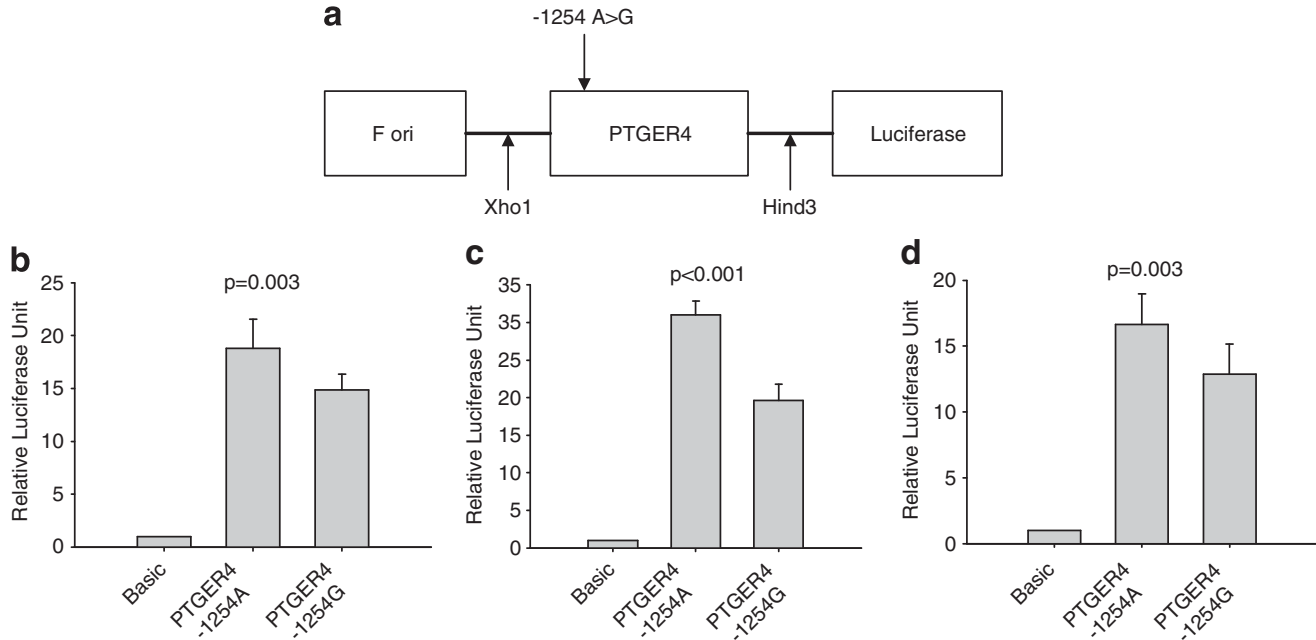

Figure 1 Effect of $-1254 \mathrm{~A}>\mathrm{G}$ polymorphism on the transcription activity of PTGER4 promoter. (a) Luciferase reporter constructs using transfected (b) HMC-1, (c) U937 and (d) Jurkat-T cell. Relative luciferase activity was represented as the ratio of the activity to the Luciferase activity in the cells transfected with the empty control vector pGL3 basic. Luciferase activity assay was performed in three independent experiments $(n=9)$.

construct compared with the PTGER4 $-1254 A$ construct in Jurkat-T cells $(P=0.003$; Figure 1c) and U937 cells $(P<0.001$; Figure $1 \mathrm{~d})$. To identify possible transcription factor-binding sites in this promoter region, transcription factor databases were searched using the CONSITE program (http://asp.ii.uib.no:8090/cgi-bin/CONSITE/ consite). As the PTGER4 $-1254 A>G$ polymorphism creates a potential SP-1 transcription factor-binding site, we chose SP-1 as a candidate transcription factor for competition assay to examine the effect of the PTGER4 polymorphism.

\section{Effects of PTGER4 - 1254A $>G$ gene polymorphism on transcriptional activity}

In an electrophoretic mobility shift assay of nuclear extracts from HMC-1 cells using a double-stranded oligonucleotide probes corresponding to PTGER4 $-1254 A>G,-1254 \mathrm{G}$ produced a specific band with higher affinity than that produced by $-1254 \mathrm{~A}$. The band disappeared in the presence of non-labeled $-1254 \mathrm{G}$ probe as a competitor, but not in the presence of non-labeled $-1254 \mathrm{~A}$ probe (Figure 2) or in the presence of the transcription factor SP-1 or nuclear factor- $\kappa \mathrm{B}$.

\section{Effect of ASA on PTGER4 mRNA expression and PGE2 production from HMC-1 cells}

PTGER4 mRNA expression was significantly decreased after ASA treatment in HMC-1 cell line at $2 \mathrm{mM}(P=0.008)$ as shown by realtime PCR (Figure 3). PGE2 level $(\mathrm{pg} / \mathrm{ml})$ was significantly decreased $(P=0.001)$ after ASA treatment, as measured by supernatant from HMC-1 cells, as shown in Figure 4.

\section{DISCUSSION}

Change in eicosanoid metabolism is widely accepted mechanism for ASA hypersensitivity; however, the detail mechanism for AICU is yet to be known. To our knowledge, this is the first study to investigate a significant association between AICU and promoter polymorphisms of PTGER4. The PTGER4 $-1254 \mathrm{~A}>\mathrm{G}$ promoter polymorphism was shown to be significantly associated with the AICU group, which was further supported by several steps of comparable functional studies.

\section{PTGER4_1254A:GGAGCCGCCCCACCCCGCGCGCC
PTGER4_1254G:GGAGCCGCCCCGCCCCGCGCGCC
SP1:ATTCGATCGGGGCGGGGCGA NF-KB:AGTTGAGGGGACTTTCCCAGG}

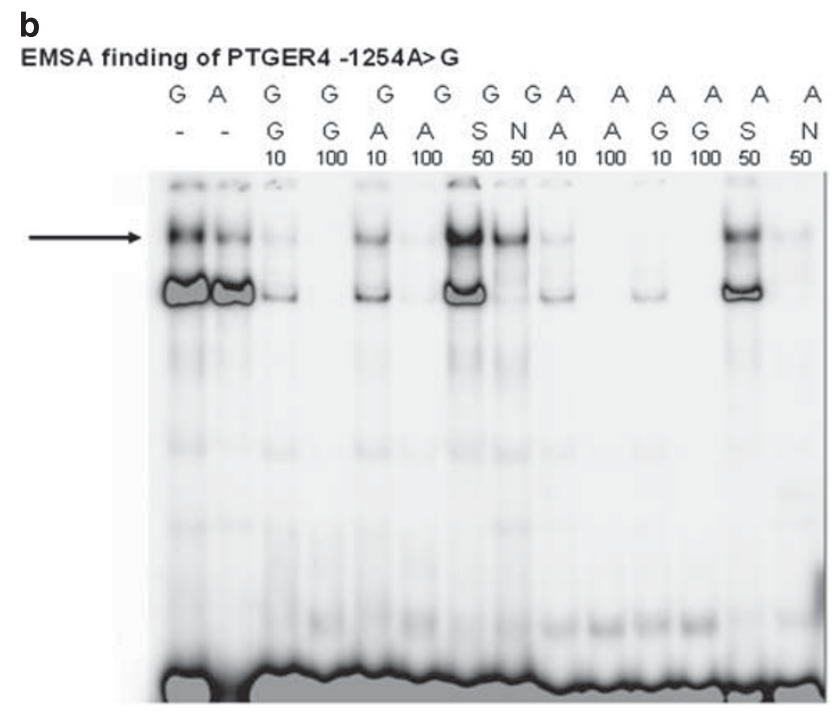

Figure 2 Results of an electrophoretic mobility shift assay for the PTGER4 - 1254A $>$ G polymorphism using nuclear extracts obtained from (a) nucelotide sequences of oligonucleotides used as probes and competitors ( $-1254 \mathrm{~T},-1254 \mathrm{C}, \mathrm{SP}-1$, nuclear factor- $\mathrm{kB}$ ). (b) Differential binding of nuclear protein to $-1254 \mathrm{G} / \mathrm{A}$ alleles in $\mathrm{HMC}-1$ cells. A full color version of this figure is available at the Journal of Human Genetics journal online.

In this study, our result indicate that $-1254 \mathrm{GG}$ is the risk-associated genotype of the PTGER4 $-1254 A>G$ promoter polymorphism in an association with AICU. It was reported in the Korean population that the polymorphisms in the PTGER1, PTGER2, PTGER3 and PTGER4 gene are known to be associated with AERD. ${ }^{7}$ Moreover, it was reported that the frequencies of GG homozygotes or heterozygotes of $-1254 \mathrm{~A}>\mathrm{G}$ were significantly higher in AERD 


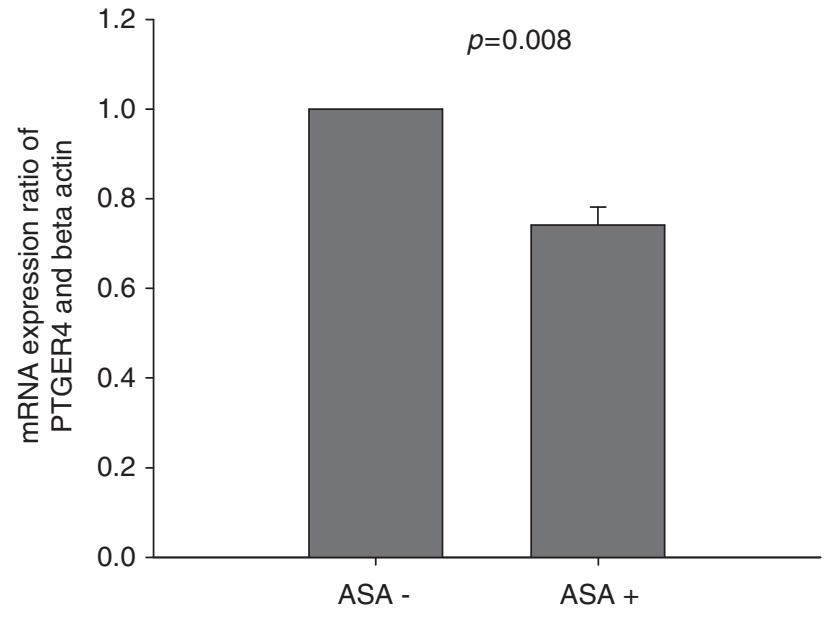

Figure 3 Expressions of PTGER4 from real-time PCR. Significant difference of mRNA expression of PTGER4 is found between aspirin-untreated and -treated human mast cell (HMC-1; $n=3 \times 3=9, P=0.008$ ).

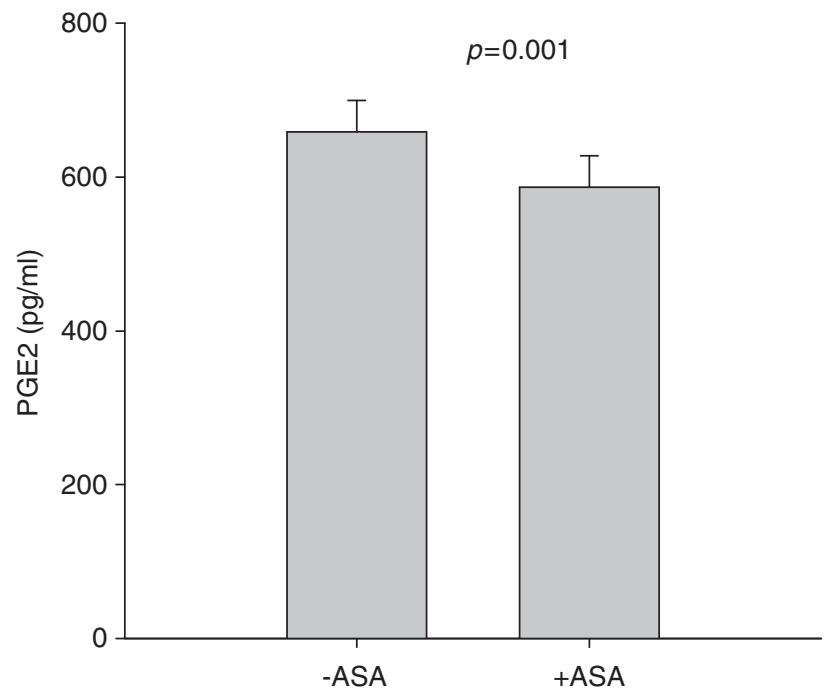

Figure 4 Effect of aspirin in PGE2 production from HMC-1 cell line. Significant difference was found in ASA-treated and -untreated sample in HMC-1 cells $(n=3 \times 3=9, P=0.001)$

patients than in ATA patients or NCs. ${ }^{16}$ This result indicates that the importance of genetic variations in PTGER4 $-1254 \mathrm{~A}>\mathrm{G}$ to ones predisposition to AICU is similar with AERD.

Mast cells are the key cell model for urticaria and release histamine and other chemical mediators, which produce urticarial symptoms, ${ }^{20}$ and mast cell activation has been reported in ASA-intolerant urticaria patients. ${ }^{21}$ Besides, PGE2 could suppress excessive anti-IgE-induced cysteinyl leukotriene production in mast cells in patients with AERD. ${ }^{12}$ Our result confirmed that the functional study of PTGER4 promoter polymorphism in HMC-1 cell line showed differential transcriptional regulation by dual-luciferase activity. The decreased promoter activity observed for PTGER4 - 1254G compared with $-1254 \mathrm{~A}$ suggests downregulation of PTGER4 expression on inflammatory cells in the presence of PTGER4 G allele. Thus, ASA exposure may cause lower expression of PTGER4 with decreased protective effect of PGE2 in subjects with this $-1254 \mathrm{G}$ allele, leading to develop AICU.

In addition, the electrophoretic mobility shift assay result demonstrated that $-1254 \mathrm{G}$-specific DNA binding was more pronounced and might have been important in the transcriptional regulation of the PTGER4 gene, compared with -1254A. It was further confirmed by competition assay, which was performed using $-1254 \mathrm{G}$ probe. The transcription factor database suggested SP-1 as a candidate transcription factor; however, SP-1 did not show any competition with the $-1254 \mathrm{G}$-specific band. This indicates that $-1254 \mathrm{G}$ allele may bind with other regulatory factor for transcriptional regulation of PTGER4 promoter polymorphism; however, it needs further study to clarify specific pathway of transcriptional regulation.

On the basis of the expression of PTGER4 receptors on mast cells, ${ }^{8}$ we performed additional in vitro functional study to confirm the effect of ASA on PTGER4 expression and PGE2 level in human mast cells. Our result showed lower mRNA expression of PTGER4 by ASA exposure with decreased production of PGE2 from HMC-1 cells. Therefore, lower promoter activity by $-1254 \mathrm{G}$ allele may be responsible for lower production of PGE2, the protective prostanoid in the airway inflammation and decreased the protective effect on AICU after ASA exposure. Alternatively, it could enhance other proinflammatory cytokines and cysteinyl leukotrienes from inflammatory cells. $^{22}$

It was previously noted that the suppression of tumor necrosis factor- $\alpha$ protein and mRNA expression by $\mathrm{PGE}^{8}{ }^{8}$ while EP4 agonist significantly reduced levels of proinflammatory cytokines and chemokines, indicating the role of EP4 activation in systemic inflammation. $^{23}$

Despite the genetic and functional study data provided here, replication studies in larger and different cohorts must be in consideration to validate these findings.

In conclusion, these findings suggest that $-1254 \mathrm{~A}>\mathrm{G}$ polymorphism of the PTGER4 gene is associated with the AICU phenotype. The PTGER4 -1254G allele with a higher frequency in AICU patients demonstrated lower promoter activity and expression of PTGER4, which will contribute to the development of AICU.

\section{CONFLICT OF INTEREST}

The authors declare no conflict of interest.

\section{ACKNOWLEDGEMENTS}

This study was supported by a grant from the Korean health 21R\&D Project, Ministry of Health, Welfare and Family Affair, ROK(A111218-11-PG01).

1 Lee, R. U. \& Stevenson, D. D. Aspirin exacerbated respiratory disease. Evaluation and Management. Allergy Asthma Immunol. Res. 3, 3-10 (2010).

2 Kim, S. H., Yang, E. M., Park, H. J., Ye, Y. M., Lee, H. Y. \& Park, H. S. Differential contribution of the CysLTR1 gene in patients with aspirin hypersensitivity. J. Clin. Immunol. 27, 613-619 (2006).

3 Palikhe, N. S., Kim, S. H., Lee, H. Y., Kim, J. H., Ye, Y. M. \& Park, H. S. Association of thromboxane A2 receptor (TBXA2R) gene polymorphism in patients with aspirinintolerant acute urticaria. Clin. Exp. Allergy 41, 179-185 (2010).

4 Snijdewint, F. G., Kalinski, P., Wierenga, E. A., Bos, J. D. \& Kapsenberg, M. L. Prostaglandin E2 differentially modulates cytokine secretion profiles of human T helper lymphocytes. J. Immunol. 150, 5321-5329 (1993).

5 Betz, M. \& Fox, B. S. Prostaglandin E2 inhibits production of Th1 lymphokines but not of Th2 lymphokines. J. Immunol. 146, 108-113 (1991).

6 Gauvreau, G. M., Watson, R. M. \& O'Byrne, P. M. Protective effects of inhaled PGE2 on allergen-induced airway responses and airway inflammation. Am. J. Respir. Crit. Care Med. 159, 31-36 (1999).

7 Park, B. L., Park, S. M., Park, J. S., Uh, S. T., Choi, J. S., Kim, Y. H. et al. Association of PTGER gene family polymorphisms with aspirin intolerant asthma in Korean asthmatics. BMB Rep. 43, 445-449 (2010). 
8 Feng, C., Beller, E. M., Bagga, S. \& Boyce, J. A. Human mast cells express multiple EP receptors for prostaglandin E2 that differentially modulate activation responses. Blood 107, 3243-3250 (2006).

9 Hartert, T. V., Dworski, R. T., Mellen, B. G., Oates, J. A., Murray, J. J. \& Sheller, J. R. Prostaglandin $E(2)$ decreases allergen-stimulated release of prostaglandin $D(2)$ in airways of subjects with asthma. Am. J. Respir. Crit. Care Med. 162, 637-640 (2000).

10 Peachell, P. T., MacGlashan, Jr D. W., Lichtenstein, L. M. \& Schleimer, R.P. Regulation of human basophil and lung mast cell function by cyclic adenosine monophosphate. J. Immunol. 140, 571-579 (1988).

11 Sestini, P., Armetti, L., Gambaro, G., Pierni, M. G., Refine, R. M. \& Sala, A. Inhaled PGE2 prevents aspirin-induced bronchoconstriction and urinary LTE4 excretion in aspirin-sensitive asthma. Am. J. Respir. Crit. Care Med. 153, 572-575 (1996).

12 Wang, X. S., Wu, A. Y., Leung, P. S. \& Lau, H. Y. PGE suppresses excessive anti-lgE induced cysteinyl leucotrienes production in mast cells of patients with aspirin exacerbated respiratory disease. Allergy 62, 620-627 (2007).

13 Palikhe, N. S., Kim, S. H. \& Park, H. S. What do we know about the genetics of aspirin intolerance? J. Clin. Pharm. Ther. 33, 465-472 (2008).

14 Katsuyama, M., Nishigaki, N., Sugimoto, Y., Morimoto, K., Negishi, M., Narumiya, S. et al. The mouse prostaglandin E receptor EP2 subtype: cloning, expression, and northern blot analysis. FEBS Lett. 372, 151-156 (1995).

15 An, S., Yang, J., So, S. W., Zeng, L. \& Goetzl, E. J. Isoforms of the EP3 subtype of human prostaglandin E2 receptor transduce both intracellular calcium and cAMP signals. Biochemistry 33, 14496-14502 (1994).
16 Kim, S. H., Kim, Y. K., Park, H. W., Jee, Y. K., Kim, S. H., Bahn, J. W. et al. Association between polymorphisms in prostanoid receptor genes and aspirin-intolerant asthma. Pharmacogenet. Genomics 17, 295-304 (2007).

17 Park, H. W., Shin, E. S., Lee, J. E., Kim, S. H., Kim, S. S., Chang, Y. S. et al. Association between genetic variations in prostaglandin E2 receptor subtype EP3 gene (Ptger3) and asthma in the Korean population. Clin. Exp. Allergy 37, 1609-1615 (2007).

18 Palikhe, N. S., Kim, S. H., Cho, B. Y., Choi, G. S., Kim, J. H., Ye, Y. M. et al. IL-13 gene polymorphisms are associated with rhinosinusitis and eosinophilic inflammation in aspirin intolerant asthma. Allergy Asthma Immunol. Res. 2, 134-140 (2010).

19 Palikhe, N. S., Kim, S. H., Cho, B. Y., Ye, Y. M., Choi, G. S., Park, H. S. et al. Genetic variability in CRTH2 polymorphism increases eotaxin-2 levels in patients with aspirin exacerbated respiratory disease. Allergy 65, 338-346 (2010).

20 Kaufman, A. \& Rosenstreich, D. L. Mast cell heterogeneity in chronic idiopathic urticaria. Ann. Allergy 65, 367-373 (1990).

21 Gamboa, P., Sanz, M. L., Caballero, M. R., Urrutia, I., Anetpara, I., Esparza, R. et al. The flow-cytometric determination of basophil activation induced by aspirin and other non-steroidal anti-inflammatory drugs (NSAIDs) is useful for in vitro diagnosis of the NSAID hypersensitivity syndrome. Clin. Exp. Allergy 34, 1448-1457 (2004).

22 Higashi, N., Mita, H., Ono, E., Fukutomi, Y., Yamaguchi, H., Kajiwara, K. et al. Profile of eicosanoid generation in aspirin-intolerant asthma and anaphylaxis assessed by new biomarkers. J. Allergy Clin. Immunol. 125, 1084-1091 (2010).

23 Shi, J., Johansson, J., Woodling, N. S., Wang, Q., Montine, T. J., Andreasson, K. et al. The prostaglandin E2 E-prostanoid 4 receptor exerts anti-inflammatory effects in brain innate immunity. J. Immunol. 184, 7207-7218 (2010). 